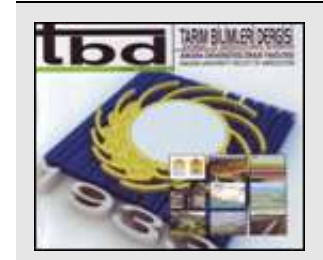

Tarım Bilimleri Dergisi Tar. Bil. Der.

Dergi web sayfası: www.agri.ankara.edu.tr/dergi
Journal of Agricultural Sciences

Journal homepage: www.agri.ankara.edu.tr/journal

\title{
Effect of Soil Organic Matter and Humates on Adsorption and Desorption Chemistry of Iodide in an Aridisol
}

\author{
Muhittin Onur AKÇA ${ }^{a}$, Sadık USTA ${ }^{a}$, Mehmet KEÇECI ${ }^{b}$, Veli UYGUR ${ }^{c}$

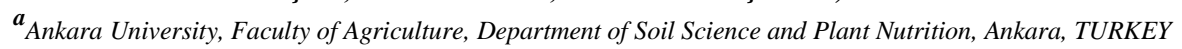

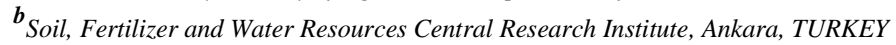

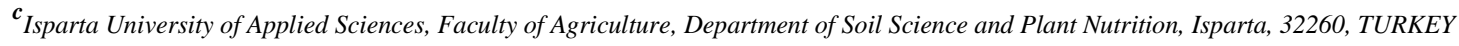

\section{ARTICLE INFO}

Research Article

Corresponding Author: Veli UYGUR, E-mail: veliuygur@isparta.edu.tr, Tel: +90 (246) 2118582

Received: 04 April 2018, Received in Revised Form: 10 September 2018, Accepted: 18 September 2018

\section{AUTHORS ORCID ID:}

(Muhittin Onur AKÇA: 0000-0003-4540-9371), (Sadık USTA: 0000-0001-5739-9962), (Mehmet KEÇECI: 0000-0003-1665-4677), (Veli UYGUR: 0000-0003-3971-7714)

\section{ABSTRACT}

The translocation of iodine (I) from soil to food chain is largely determined by its adsorption/desorption reaction in soils. In this study, the effects of commercial humates (HA) applied on an Aridisol and indigenous soil organic matter (SOM) on the adsorption and desorption of iodide were investigated. For this reason, $1 \%$ and $3 \%$ HA (w/w) were incorporated into the whole soil (WS) and organic matter free $(\mathrm{OMF})$ soil samples. Then soil samples were equilibrated with $0,2,4,6,8$ and $10 \mathrm{mg} \mathrm{L}^{-1}$ iodide solution prepared in 0.01 molar $\mathrm{CaCl}_{2}$ for $40 \mathrm{~h}$. The sorption data were better described by Langmuir isotherm $\left(\mathrm{R}^{2}=0.938\right)$ than Freundlich isotherm $\left(\mathrm{R}^{2}=0.763\right)$. The
\end{abstract}

Keywords: Humates; Organic matter; Iodide; Adsorption; Desorption

\begin{abstract}
Langmuir sorption maximum of WS was $19.8 \mathrm{mg} \mathrm{kg}^{-1}$. Freundlich isotherm parameters were $\mathrm{n}=0.89$ and $\mathrm{K}_{\mathrm{f}}=2.165$. Sorption maximum of OMF soil significantly increased up to $35.5 \mathrm{mg} \mathrm{kg}^{-1}$. HA applications reduced iodide sorption maximum of both WS and organic OMF soil samples. Desorption rate of the WS ranged between $0-15.3 \%$ whereas it decreased $0-0.65 \%$ upon removal OM. HA treatments, in general, reduced the desorption rates. However, increasing HA application resulted in higher desorption ratio in both WS and OMF soils. Consequently, either SOM or HA has preeminent role in the adsorption-desorption chemistry in soils.
\end{abstract}

\section{Introduction}

Iodine (I) is an essential nutrient element for mankind and animals, despite a limited number of researches about its essentiality for plants, animal and plant-origin foods should contain sufficient amounts of I. Approximately one-third of the world's population is suffering inadequate I intake (Andersson et al 2012). Iodine is an important micro element for all mammals' health, and an adult human being is required to have 100-150 $\mu \mathrm{g} \mathrm{day}^{-1}$ in the diet (Johnson 2003). Despite average I concentration in soils $\left(2.8 \mathrm{mg} \mathrm{kg}^{-1}\right)$ are generally higher than those in parent materials $\left(0.5 \mathrm{mg} \mathrm{kg}^{-1}\right)\left(\mathrm{Kabata}^{-}\right.$ Pendias 2011), plants suffer very low I concentration (0.005-10.4 $\mathrm{mg} \mathrm{kg}^{-1}$ ) (Shacklette \& Cuthbert 1967) leading I deficiency-induced diseases such as goiter, cretinism, low IQ, abortions, birth anomalies and higher neonatal death (Laurberg et al 2010) in animal and/or human being. Traditionally extracts of kelp and seaweeds had long been used to treat goitre (Alejandro et al 2017) because of their very high I concentration; currently cabbage (leaves) and onion (bulb) are of terrestrial plants contain relatively higher I (Shacklette \& Cuthbert 1967) can alternatively be included in dietary intake at larger portions. Therefore, it is essential to understand the ability of a soil, which is the main source of the food chain, to bind I and meet the requirement of plants. Since supplemental intake of I salts to correct its deficiency can be 
problematic, the occurrence of sufficient soil-I should be main goal to maintain well-being ecology of the soil-plantanimal-mankind food chain. On the other hand, the mechanisms controlling I transfer to the food chain in terrestrial environments and the components of the global I cycles have not yet been clearly elucidated (Johnson 2003). For this reason, there is a need to understand the I-soil interactions, plant uptake and metabolisms. The researchers have proved that $\mathrm{OM}$ is critical in the partition of $\mathrm{I}$ in the soil environment. The investigations revealed the relation between SOM content and I concentrations and humus is the primary reservoir of I in the soil (Dai et al 2009; Smyth \& Johnson 2011; $\mathrm{Xu}$ et al 2011).

Humates (HA) is a colloidal fraction of humus containing both aliphatic and aromatic compounds. It has been shown that HA has a large surface area and is highly effective in determining I dynamics in the soil due to its occurrence in the soil organic matter, SOM (Francois 1987; Hansen et al 2011; Xu et al 2011). Although there are some structural differences between HA used in agriculture and indigenous soil humic substances, it is clear that the existing functional groups are similar. For this reason, the relationship between HA and I is critical to understand the dynamics of the I-HA complexes in the soil. Best of our knowledge, there are limited number of works in the literature elucidating I and HA relation in the soil environment (Christiansen \& Carlsen 1991; Reiller et al 2006; Choung et al 2013). In general, the reaction between I and HA has not been clearly demonstrated since most of the studies had used complex aerosols-like environments consisting of other I-reactive components. These complexities can be explained as follows: the HA-I complex is mainly reduced towards reactive intermediates such as $\mathrm{I}_{2}$ or HOI; followed by electrophilic substitution reactions with electron donor groups on HA (Francois 1987). Whitehead (1974) reported that phenolic and amino acid groups with a weak acid character on HA are the potential binding sites for I.

In this study, the effects of SOM and HA, both of which can regulate to some extent I cycle in soil environment, on adsorption/desorption properties of iodide on an Aridisol were investigated. For this purpose, adsorption isotherms and desorption ratio of iodide by WS and OMF soil treated with two doses of HA were obtained.

\section{Material and Methods}

\subsection{Sampling location and treatments}

Soil sampling site, Polatlı Agricultural Estate Farms, situates in Polatlı, Ankara $\left(39^{\circ} \mathrm{N} 32^{\circ} \mathrm{E}\right)$. The soil, Yüzükbaşı soil series, is classified as a typical Aridisol. The composite surface soil samples $(0-30 \mathrm{~cm})$ were sieved through $2 \mathrm{~mm}$ for physical and chemical soil analyses. SOM was oxidised by analytical reagent grade $30 \% \mathrm{H}_{2} \mathrm{O}_{2}$ (Hartge 1971) and dried at $40{ }^{\circ} \mathrm{C}$ till constant weight. Then both whole soil (WS) and organic matter free (OMF) soils were incorporated in $1 \%$ and $3 \% \mathrm{HA}$ on weight bases and left incubation at $28{ }^{\circ} \mathrm{C}$ constant temperature and $70 \%$ of field capacity in dark for 60 days. Then the soil samples were subjected to the adsorption/desorption experiments.

\subsection{Soil analyses}

The descriptive soil properties were analysed according to common methods given by Sparks et al (1996). Analysed parameters were: both soil $\mathrm{pH}$ and electrical conductivity in saturation paste, cation exchange capacity (CEC) by $\mathrm{Na}$ acetate saturation, calcium carbonate equivalent by Scheibler calcimeter, $\mathrm{OM}$ by $\mathrm{K}_{2} \mathrm{Cr}_{2} \mathrm{O}_{7}$ wet oxidation, available potassium $(\mathrm{K})$ extracted by neutral ammonium acetate, and available phosphorus extracted by $0.5 \mathrm{M} \mathrm{NaHCO}_{3}$ at $\mathrm{pH} 8.5$. Soil texture was measured by Bouyoucous hydrometer method (Gee \& Bauder 1986).

\subsection{Descriptive analysis of commercial humate}

The HA was kindly supplied by "Biyotar Corporation". The following properties of HA were determined: total humic acid + fulvic acid (TS 5869 ISO 5073), total nitrogen (Kjeldahl method), pH and EC (in 1:10 HA: distilled water) and total concentrations of $\mathrm{P}, \mathrm{K}, \mathrm{Fe}, \mathrm{Cu}, \mathrm{Zn}, \mathrm{Mn}, \mathrm{Cr}, \mathrm{Ni}, \mathrm{Pb}$, and $\mathrm{Cd}$ in wet digests $\left(\mathrm{HNO}_{3} / \mathrm{HClO}_{4}\right)$ were determined by $\mathrm{ICP}$ OES. The properties of HA were given in Table 1. 
Table 1- Chemical properties of the commercial humate used in the experiment

\begin{tabular}{lrlr}
\hline Parameters & Results & Parameters & Results \\
\hline Total humic acid+fulvic acid (\%) & 66.4 & Total copper $\left(\mathrm{mg} \mathrm{kg}^{-1}\right)$ & 24.6 \\
Total N (\%) & 0.73 & Total zinc $\left(\mathrm{mg} \mathrm{kg}^{-1}\right)$ & 92.7 \\
Moisture $(\%)$ & 7.94 & Total manganese $\left(\mathrm{mg} \mathrm{kg}^{-1}\right)$ & 131.2 \\
pH ${ }_{\text {H2O }}(1 / 10)$ & 8.65 & Total nickel $\left(\mathrm{mg} \mathrm{kg}^{-1}\right)$ & 89.3 \\
EC $\left(1 / 10, \mathrm{mS} \mathrm{cm}^{-1}\right)$ & 6.38 & Total chromium $\left(\mathrm{mg} \mathrm{kg}^{-1}\right)$ & 30.2 \\
Total phosphorus $(\%)$ & 0.54 & Total lead $\left.(\mathrm{mg} \mathrm{kg})^{-1}\right)$ & 23.0 \\
Total potassium $(\%)$ & 9.89 & Total cadmium $\left(\mathrm{mg} \mathrm{kg}^{-1}\right)$ & 3.00 \\
Total iron $(\%)$ & 1.14 & & \\
\hline
\end{tabular}

\subsection{Adsorption-desorption experiments}

\subsubsection{Adsorption}

Prior to sorption experiment, soil samples were passed through $0.5 \mathrm{~mm}$ sieve. Then $2.5 \mathrm{~g}$ of WS, OMF soil, and HAtreated WS and OMF soil samples were put into $50 \mathrm{~mL}$ polypropylene centrifuge tubes with three-fold. Soils were then equilibrated with $25 \mathrm{~mL}$ of $0,2,4,6,8$, and $10 \mathrm{mg} \mathrm{I} \mathrm{L}^{-1}$ (KI) solution prepared in the $0.01 \mathrm{M} \mathrm{CaCl}_{2}$ background solution at $25{ }^{\circ} \mathrm{C}$ for $40 \mathrm{~h}$. The supernatant solutions were obtained by centrifugation at $10000 \mathrm{rpm}$ for 5 min and subsequently filtered through $0.22 \mathrm{~mm}$ filter paper. Then iodide equilibrium concentrations of the filtrates were determined by an ion meter (Proline Plus, Iodine Comb. ISE/BNC). The deviation (RSD) was always less than 5\% between the replicates.

\subsubsection{Desorption}

In order to desorb the adsorbed iodide $25 \mathrm{~mL}$ of background solution was added and the suspensions were then shaken on a reciprocal shaker at $25^{\circ} \mathrm{C}$ for $40 \mathrm{~h}$. The supernatants were separated as described in the adsorption study.

\subsubsection{Adsorption isotherms}

The amount of adsorbed iodide concentration was calculated from the difference between the initial and equilibrium concentrations. The obtained sorption data were subjected to the Langmuir and Freundlich adsorption models given below:

Linear Langmuir Isotherm: $\mathrm{Ce} / \mathrm{Si}=\mathrm{Ce} / \mathrm{b}+1 / \mathrm{kb}$

Freundlich isotherm, $\mathrm{Si}=\mathrm{K}_{\mathrm{f}} \mathrm{Ce}^{\mathrm{n}}$, can be linearized as $\log (\mathrm{Si})=\log \mathrm{K}_{\mathrm{f}}+\mathrm{n} \log \mathrm{C}_{\mathrm{e}}$

Where; $\mathrm{Si}$, the amount of iodide adsorbed $\left(\mathrm{mg} \mathrm{kg}^{-1}\right)$; Ce equilibrium concentration $\left(\mathrm{mg} \mathrm{L}^{-1}\right)$; $\mathrm{k}$ and $\mathrm{b}$ are coefficients related to bounding energy and maximum adsorption; $\mathrm{K}_{\mathrm{f}}$ and $\mathrm{n}$ are coefficients.

\subsection{Statistical analysis}

The confirmation of the sorption data to the adsorption isotherms was tested by regression analysis. The isotherm adsorption parameters were subjected to one-way ANOVA to reveal the effect of SOM and the added HA. Mean separation of the treatments was performed by Duncan test in MSTAT-C environment.

\section{Results and Discussion}

The experimental soil was clay textured, slightly alkaline reaction, non-saline, very rich calcium carbonate equivalent; poor in OM, total nitrogen content and available $\mathrm{P}$ concentration and sufficient available K concentration (Table 2). 
Table 2- Descriptive physicochemical properties of the experimental soil

\begin{tabular}{lll}
\hline Soil Properties & Unit & Results \\
\hline & $\%$ Clay & 39.81 \\
Textural class $(\mathrm{C})$ & $\%$ Silt & 38.25 \\
& $\%$ Sand & 21.94 \\
\hline $\mathrm{pH}($ Saturation paste) & - & 7.86 \\
Electrical conductivity (EC) & $\mathrm{dS} \mathrm{m}^{-1}$ & 0.252 \\
Calcium carbonate equivalent $\left(\mathrm{CaCO}_{3}\right)$ & $\mathrm{g} \mathrm{kg}^{-1}$ & 169 \\
Organic matter & $\mathrm{g} \mathrm{kg}^{-1}$ & 7.00 \\
Aggregate stability & $\%$ & 51.40 \\
Total nitrogen & $\%$ & 0.035 \\
Available potassium & $\mathrm{mg} \mathrm{kg}^{-1}$ & 347 \\
Available phosphorus & $\mathrm{mg} \mathrm{kg}^{-1}$ & 2.40 \\
Iodine & $\mathrm{mg} \mathrm{kg}^{-1}$ & 0.0047 \\
\hline
\end{tabular}

\subsection{Isotherm parameters}

\subsubsection{Adsorption parameters of WS}

Iodide sorption parameters of WS and OMF were given in Table 3. Sorption data were better described by Langmuir isotherm because the determination coefficient of Langmuir isotherm $\left(R^{2}=0.9376\right)$ was higher than the one belonging to Freundlich isotherm $\left(\mathrm{R}^{2}=0.7626\right)$. However, determination coefficients of Langmuir isotherm were even improved upon HA treatment to 0.9991 and 0.9999 for $1 \%$ and 3\% HA-treated WS (HATWS) respectively. In contrast, Freundlich isotherm described sorption data progressively poorer for HATWS. Calculated Langmuir maximum sorptions of HATWS were $19.8,17.1$ and $15.0 \mathrm{mg} \mathrm{kg}^{-1}$ for 0,1 and $3 \% \mathrm{HA}$ treatments, respectively. Whereas bounding energy coefficient significantly increased upon HA treatment as $0.753,6.95$, and $37.0 \mathrm{~mL} \mathrm{~g}^{-1}$ for 0,1 , and $3 \% \mathrm{HA}$ treatments, respectively.

Table 3- Multiple comparison of sorption isotherm parameters

\begin{tabular}{|c|c|c|c|c|c|c|c|}
\hline \multirow[b]{2}{*}{ Soil } & \multirow[b]{2}{*}{ Treatments } & \multicolumn{3}{|c|}{ Langmuir isotherm } & \multicolumn{3}{|c|}{ Freundlich isotherm } \\
\hline & & $\begin{array}{l}b \\
m g k^{-1}\end{array}$ & $\begin{array}{l}k \\
m L g^{-1}\end{array}$ & $R^{2}$ & $n$ & $K_{f}$ & $R^{2}$ \\
\hline \multirow{3}{*}{ WS } & WS & $19.8 \mathrm{~b}$ & $0.753 \mathrm{e}$ & 0.9376 & $0.89 \mathrm{~b}$ & $2.10 \mathrm{~d}$ & 0.7626 \\
\hline & $1 \%$ HATWS & $17.1 \mathrm{~cd}$ & $6.95 \mathrm{~d}$ & 0.9991 & $1.193 \mathrm{ab}$ & $3.71 \mathrm{c}$ & 0.4557 \\
\hline & $3 \%$ HATWS & $15.0 \mathrm{e}$ & $37.0 \mathrm{a}$ & 0.9999 & $1.06 \mathrm{ab}$ & $3.30 \mathrm{c}$ & 0.4556 \\
\hline \multirow{3}{*}{$\mathrm{OMF}$} & OMF & $35.5 \mathrm{a}$ & $0.58 \mathrm{e}$ & 0.8831 & $0.74 \mathrm{ab}$ & $2.69 \mathrm{a}$ & 0.9109 \\
\hline & $1 \%$ НАТОМF & $17.7 \mathrm{c}$ & $28.4 \mathrm{~b}$ & 0.9999 & $1.27 \mathrm{a}$ & $4.30 \mathrm{~b}$ & 0.3935 \\
\hline & $3 \%$ HАTOMF & $15.8 \mathrm{de}$ & $15.4 \mathrm{c}$ & 0.9998 & $1.22 \mathrm{ab}$ & $3.61 \mathrm{c}$ & 0.4489 \\
\hline
\end{tabular}

WS, whole soil; OMF, organic matter free soil; HAT, humic acid treatment; b, adsorption maximum; k, bonding energy coefficients of Langmuir isotherm; $n$, a measure of intensity of adsorption and; $\mathrm{K}_{\mathrm{f}}$, indicator of maximum adsorption of Freundlich isotherm. Different letters in the same column indicate significant differences among the treatments

HA-induced Freundlich adsorption intensity coefficients (n) were $0.89,1.93$ and 1.06 for 0 , 1, and $3 \%$ HA treatments, respectively (Table 3 ). The respective $\mathrm{K}_{\mathrm{f}}$ coefficients were calculated as $2.10,3.71$, and $3.30 \mathrm{mg} \mathrm{kg}^{-1}$. $\mathrm{HA}_{\text {incorporation }}$ increased the $\mathrm{K}_{\mathrm{f}}$ constant when compared with the original soil.

\subsubsection{Adsorption isotherm parameters of organic matter free soil}

Freundlich isotherm $\left(\mathrm{R}^{2}=0.9109\right)$ slightly better described sorption data of OMF soil whereas sorption data of HA-treated organic matter free (HATOMF) soils clearly conformed Langmuir isotherm to a determination coefficient above 0.9998 . Freundlich isotherm, on the other hand, failed to describe sorption data showing a determination coefficient below 0.4489 . Langmuir sorption maximum progressively decreased by HA application in the OMF soil as $35.5,17.7$ and $15.8 \mathrm{mg} \mathrm{kg}^{-1}$ 
for OMF, 1 and 3\% HA, respectively. As small as 1\% HA addition to soil resulted in 50.1\% reduction in the sorption maximum. The calculated bonding energy coefficients did not show consistent increases that were $0.58,28.4$, and 15.4 for 0,1 , and $3 \%$ HA treatments.

The adsorption intensity of OMF soil (0.74) was significantly smaller than those obtained for HATOMF (Table 3 ). There were no differences between the HA treatments. $\mathrm{K}_{\mathrm{f}}$ coefficients which are indicators of adsorption capacity ranged between 2.69 and 4.30. The highest $\mathrm{K}_{\mathrm{f}}$ value was obtained for $1 \%$ HA treatment. Typically slope of Freundlich isotherm is smaller than " 1 " as observed in the OMF soil. However, HA application increased slope above "1" suggesting a different mechanism.

As shown in Table 3, the highest adsorption maximum value was found in OMF. HA treatments had an apparent decrease in OMF soil samples comparing to the WS. This could be an indication of interaction between the indigenous and commercial HA which significantly decreases sorption sites of HA for I. Commercial humates are salts of humic substances, which are more soluble and thus more reactive in soil (Lobartini et al 1992; Lyons \& Genc 2016). Humic substances can construct random manner linkages (Garcia et al 2016) with even SOM or clay minerals resulting in extraordinarily complex materials. Newly formed organo-mineral complexes in the soil, in fact, block a significant portion of I sorption sites in OMF soil sample. On the other hand, anionic nature of commercial HA which generally preferentially adsorbed on the clay surfaces over anions such as phosphates (Uygur \& Karabatak 2009). Dai et al (2009) pointed out the significance of the OM in soil environments in controlling I geochemistry. Adsorption studies with dissolved humic acids indicated that the contribution of clay fraction was over 90\% (Pan et al 2010) which suggest clay fraction in this study can be responsible for very high sorption maximum in the OMF.

\subsection{Effects of treatments on desorption ratio}

\subsubsection{Desorption in whole soil}

The desorption ratio (DR) dependent on the initial concentration and treatments of the soil are summarized in Table 4. The highest value for WS without HA was found to be $15.08 \%$ at $4 \mathrm{mg} \mathrm{L}^{-1}$ initial concentration. Further increase in the initial concentration did not improve the desorbability of iodide. Despite DRs in 1\% HATWS were smaller than the ones obtained from WS there was a gradual continuous increase in DR upon 1\% HA treatment. The maximum value (6.28\%) was therefore recorded for $10 \mathrm{mg} \mathrm{I} \mathrm{L}^{-1}$ (Table 4). The higher HA treatment (3\% HA) resulted in the higher DR for each respective initial concentration. The maximum desorption was obtained at maximum initial concentration. The equilibrium $\mathrm{pH}$ at desorption remained relatively very narrow range between 7.76-7.91.

Table 4- The effects of initial iodine concentration on the desorbability ratio of iodine-adsorbed and equilibrium pH

\begin{tabular}{|c|c|c|c|c|c|c|c|c|c|c|c|c|}
\hline \multirow{3}{*}{$\begin{array}{c}I C \\
\left(m g k g^{-1}\right)\end{array}$} & \multicolumn{6}{|c|}{ Whole soil } & \multicolumn{6}{|c|}{ Organic matter-free soil } \\
\hline & \multicolumn{2}{|l|}{$0 \% H A T$} & \multicolumn{2}{|l|}{$1 \% H A T$} & \multicolumn{2}{|l|}{$3 \% H A T$} & \multicolumn{2}{|l|}{$0 \% H A T$} & \multicolumn{2}{|l|}{$1 \% H A T$} & \multicolumn{2}{|l|}{$3 \%$ HAT } \\
\hline & $D R(\%)$ & $p H^{*}$ & $D R(\%)$ & $p H$ & $D R(\%)$ & $p H$ & $D R(\%)$ & $p H$ & $D R(\%)$ & $p H$ & $D R(\%)$ & $p H$ \\
\hline 0 & 0.00 & 7.77 & 0.00 & 7.76 & 0.00 & 7.78 & 0.00 & 7.52 & 0.00 & 7.75 & 0.00 & 7.76 \\
\hline 2 & 8.35 & 7.79 & 1.08 & 7.77 & 4.14 & 7.79 & 0.44 & 7.65 & 0.90 & 7.76 & 2.60 & 7.77 \\
\hline 4 & 15.08 & 7.80 & 2.21 & 7.80 & 5.02 & 7.82 & 0.51 & 7.77 & 1.64 & 7.81 & 4.56 & 7.78 \\
\hline 6 & 13.16 & 7.81 & 3.08 & 7.83 & 5.98 & 7.83 & 0.48 & 7.77 & 2.36 & 7.81 & 4.80 & 7.81 \\
\hline 8 & 13.57 & 7.83 & 4.27 & 7.88 & 8.88 & 7.85 & 0.51 & 7.78 & 3.57 & 7.86 & 6.48 & 7.84 \\
\hline 10 & 15.31 & 7.83 & 6.28 & 7.91 & 9.81 & 7.92 & 0.65 & 7.79 & 4.78 & 7.87 & 7.94 & 7.90 \\
\hline
\end{tabular}

IC, initial concentration; HAT, humic acid treatment; DR, desorption ratio of the adsorbed-iodine; *, equilibrium pH for desorption study

\subsubsection{Desorption in organic matter-free soil}

The DRs of iodide drastically reduced down $0.44-0.65 \%$ range upon removal of SOM (Table 4). The equilibrium pH varied relatively larger range between 7.52-7.79. The higher rate of HA addition-induced increases in the desorption rate 
that 3\% HA treatment was more effective below initial concentrations of $4 \mathrm{mg} \mathrm{L}^{-1}$. The maximum desorption ratios for both HA treatments were obtained at $10 \mathrm{mg} \mathrm{I} \mathrm{L}^{-1}$ initial concentration that was $4.78 \%$ for $1 \% \mathrm{HA}$ and $7.94 \%$ for $3 \% \mathrm{HA}$. Neither initial concentrations of iodide nor HA application rate affected equilibrium $\mathrm{pH}$ (7.76-7.90) of desorption supernatants.

\subsection{Comparison of adsorption/desorption isotherms}

Very low desorption ratios of iodide indicated that there is likely to be apparent hysteresis between adsorption-desorption isotherms which can be caused by strong binding energy of iodide to surfaces that can be attributed to chemisorption reactions. Commercial humate incorporation into either WS or OMF soils caused an increase in DR. This suggests that humate can be preferentially adsorbed on the surface which would inhibit specific adsorption of iodide. As a result, desorption ratios increased as higher amounts of HA incorporation. Despite some reduction in the specific sorption sites they are not fully occupied by HA. On the other hand, HA may have some non-specific sorption sites as indicated by rateinduced increases in the desorption ratios.

An apparent increase in the sorption maximum from 19.8 to $35.5 \mathrm{mg} \mathrm{kg}^{-1}$ upon removal of SOM put forward the significance of the OM in sorption mechanism of iodide. SOM is to form organo-mineral complexes with clay minerals which could be critical for partitioning of external iodide. Substantial decreases in the desorbability of iodide in OMF soil and increases after HA incorporation indicated that well-humified organic substances are to block specific sorption sites on the colloidal mineral surfaces. Dai et al (2004) also found that SOM had a significant negative effect on iodate adsorption and that they found iodate adsorption capacities of $9-34 \mathrm{mg} \mathrm{kg}^{-1}$ in the soil studied.

A variety of soil minerals such as calcite, chlorite, epidote, goethite, gypsum, hematite, kaolinite, bentonite, muscovite, and quartz showed little iodide or iodate adsorption at alkaline $\mathrm{pH}$ range of 7.5 and 8 due to the existence of little $\mathrm{pH}$ dependent positive charges (Ticknor \& Cho 1990) and negative charges on clay minerals repel iodide anion. Similarly, alluvial soils retained as little as $1.4-4 \%$ of the I added whereas only $1.35-4.1 \%$ of the I-adsorbed was desorbable (Nath et al 2010).

The OM present in the soil appears to have an adverse effect on iodide adsorption. In such situation, the reaction of iodide with soluble HA should also be regarded. In contrast, Merzweiler et al (1987) reported I contents of 220 soil samples were highly correlated with the SOM. In a similar manner, the sorption of $\mathrm{I}^{-}$and $\mathrm{IO}_{3}$ on humic acid was found substantially higher than those of clay minerals indicating a specific role of SOM in I retention in soils (Muramatsu et al 1990). This controversial situation may be explained by the preferences of soil positive charges for OM over I in time, and added I can only react with positive charges of OM. At this point, the affinity of humate surfaces and soluble humate to iodide is a matter of fact in our case. The data suggested that HA used in this study can have relatively smaller amounts of physisorption sites than the indigenous soil organic matter as indicated lower desorbability in HATWS. On the other hand, the added HA can be a structural component of SOM during the incubation period of the soil as indicated similar desorption ratio in HA treated both WS and OMF soil samples (Table 4). HA can fix significant amounts of iodide by inner-sphere complexes as well. Dai et al (2004) reported that SOM is an adverse and significant effect on I adsorption and that they found iodate adsorption capacities in soil between 9-34 mg kg-1. In contrast, McNally (2011) reported that clay minerals and iron oxides were more effective than SOM in I adsorption. Whitehead (1978) related very high sorption capacity of soils to clay and OM forming under weathering conditions especially in a very high precipitation induced environment. This strong binding, in turn, could be the reason for geochemical I deficiency and goiter disease. There are however many reports pointing out a specific role in I adsorption in soils (Whitehead 1973; Lieser \& Steinkopff 1989; Akca et al 2014).

\section{Conclusions}

The results of this study indicated that the effect of SOM on the adsorption and desorption of I was critical. Either indigenous SOM or incorporated HA reduced the sorption sites on the sesquioxides and clay minerals whereas the formation such organo-mineral complexes are to increase the bioavailability of I in soils. Despite HA applications increased the bioavailability of added I in the studied soil, different soil properties can have different impacts on the adsorption processes. Therefore further researches may be needed by using soils with different physicochemical properties and even in the model soil component systems. 


\section{Acknowledgements}

This study was financially supported by the Scientific Research Project Centre of Ankara University with the project number "13B4347001".

\section{References}

Akca M O, Usta S \& Keçeci M (2014). Kireçli ana materyal üzerinde oluşmuş bir toprakta iyot adsorpsiyonu ve desorpsiyonu. Toprak Bilimi ve Bitki Besleme Dergisi 2(2): 57-69

Alejandro H B, Camus C, Infante J, Neori A, Israel Á, Hernández-González M C, Pereda S V, Gomez-Pinchetti J L, Golberg A, Tadmor-Shalev N \& Critchley A T (2017). Seaweed production: overview of the global state of exploitation, farming and emerging research activity. European Journal of Phycology 52: 391-406

Andersson M, Karumbunathan V \& Zimmermann M B (2012). Global iodine status in 2011 and trends over the past decade. Journal of Nutrition 142(4): 744-750

Choung S, Um W, Kim M \& Kim M G (2013). Uptake mechanism for iodine species to black carbon. Environmental Science \& Technology 47(18): 10349-10355

Christiansen J V \& Carlsen L (1991). Enzymatically controlled iodination reactions in the terrestrial environment. Radiochimica Acta 52(2): 327-334

Dai J L, Zhu Y G, Zhang M \& Huang Y Z (2004). Selecting iodine-enriched vegetables and the residual effect of iodate application to soil. Biological Trace Element Research 101(3): 265-276

Dai J L, Zhang M, Hu Q H, Huang Y Z, Wang R Q \& Zhu Y G (2009). Adsorption and desorption of iodine by various Chinese soils: II. Iodide and iodate. Geoderma 153(1-2): 130-135

Francois R (1987). The influence of humic substances on the geochemistry of iodine in nearshore and hemipelagic marine sediments. Geochimica et Cosmochimica Acta 51(9): 2417-2427

Garcia A C, De Souza L G A, Pereira M G, Castro R N, Garcia-Mina J M, Zonta E, Lisboa F J G \& Berbera R L L (2016). Structureproperty-function relationship in humic substances to explain the biological activity in plants. Scientific Reports 6: 20798

Gee G \& Bauder J (1986). Particle-size analysis. In: A Klute (Ed), Methods of soil Analysis, Physical and Mineralogical Methods, SSSA, Wisconsin, pp. 383-409

Hansen V, Roos P, Aldahan A, Hou X \& Possnert G (2011). Partition of iodine ( ${ }^{129}$ I and $\left.{ }^{127} \mathrm{I}\right)$ isotopes in soils and marine sediments. Journal of Environmental Radioactivity 102(12): 1096-1104

Hartge K H (1971). Die Physikalische Untersuchung Von Böden. Enke Verlag Stuttgart

Johnson C C (2003). The geochemistry of iodine and its application to environmental strategies for reducing the risks from iodine deficiency disorders (IDD). British Geological Survey, DFID kar project R7411, Report CR/03/057N

Kabata-Pendias A (2011). Trace Elements in Soils and Plants. CRC Press, Boca Raton

Laurberg P, Cerqueira C, Ovesen L, Rasmussen L B, Perrild H, Andersen S, Pedersen I B \& Carlé A (2010). Iodine intake as a determinant of thyroid disorders in populations. Best Practice \& Research Clinical Endocrinology \& Metabolism 24(1): 13-27

Lieser K H \& Steinkopff T (1989). Chemistry of radioactive iodine in the hydrosphere and in the geosphere. Radiochimica Acta 46(1): $49-55$

Lobartini J C, Tan K H, Rema J A, Gingle A R, Pape C \& Himmelsbach D S (1992). The geochemical nature and agricultural importance of commercial humic matter. Science of the Total Environment 113(1-2): 1-15

Lyons G \& Genc Y (2016). Commercial humates in agriculture: real substance or smoke and mirrors? Agronomy 6(4): 50 
McNally S R (2011). The status of iodine and selenium in waikato soils (Thesis, Master of Science (MSc). University of Waikato, Hamilton, New Zealand

Merzweiler A, Richter D, Dahnert R, \& Felgentrager HJ (1987) Occurrence of iodine in GDR soils used for agricultural production. Archiv Fur Acker Und Pflanzenbau Und Bodenkunde-Archives of Agronomy and Soil Science 31(3): 213-217

Muramatsu Y, Uchida S, Sriyotha P \& Sriyotha K (1990). Some considerations on the sorption and desorption phenomena of iodide and iodate on soil. Water, Air and Soil Pollution 49(1-2): 125-138

Nath T, Priyankar R \& Amitava R (2010). Sorption and desorption behaviour of iodine in alluvial soils of Varanasi, India. Agricultura (Slovenia) 7(2): 9-14

Pan B, Tao S, Dawson R W \& Xing B S (2010). Formation of organo-mineral complexes as affected by particle size, pH, and dry-wet cycles. Australian Journal of Soil Research 48(8): 713-719

Reiller P, Mercier-BIon F, Gimenez N, Barre N \& Miserque F (2006). Iodination of humic acid samples from different origins. Radiochimica Acta 94: 739-745

Shacklette H T \& Cuthbert M E (1967). Iodine content of plant groups as influenced by variation in rock and soil type. Geological Society of America (Special Papers) 90: 31

Smyth D \& Johnson C C (2011). Distribution of iodine in soils of Northern Ireland. Geochemistry Exploration Environment Analysis 11(1): $25-39$

Sparks D L, Page A L, Helmke P A, Loeppert R H, Soltanpour P N, Tabatbai M A, Jhonston C T \& Sumner M E (1996). Methods of Soil Analysis, Part 3 Chemical Methods. SSSA/ ASA, Wisconsin, USA

Ticknor K V \& Cho Y H (1990). Interaction of iodide and iodate with granitic fracture-filling minerals. Journal of Radioanalytical and Nuclear Chemistry 140(1): 75-90

TS 5869 ISO 5073. Toplam (humik+fulvik) asit tayini “metodu. Türk Standartları Enstitüsü, Ankara, 2003

Uygur V \& Karabatak I (2009). The effect of organic amendments on mineral phosphate fractions in calcareous soils. Journal of Plant Nutrition and Soil Science 172(3): 336-345

Whitehead D C (1973). The sorption of iodide by soils as influenced by equilibrium conditions and soil properties. Journal of the Science of Food and Agriculture 24(5): 547-556

Whitehead D C (1974). The influence of organic matter, chalk and sesquioxides on the solubility of iodide, elemental iodine and iodate incubated with soil. European Journal of Soil Science 25(4): 461-470

Whitehead D C (1978). Iodine in soil profiles in relation and aluminium oxides and organic matter. Europen Journal of Soil Science 29(1): 88-94

Xu C, Zhang S J, Ho Y F, Miller E J, Roberts K A, Li H P, Schwehr K A, Otosaka S, Kaplan D I, Brinkmeyer R, Yeager C M \& Santschi P H (2011). Is soil natural organic matter a sink or source for mobile radioiodine $\left({ }^{129} \mathrm{I}\right)$ at the Savannah River Site? Geochimica et Cosmochimica Acta 75(19): 5716-5735 